\title{
Inspiration point in design: The example of basic design class assignments
}

\author{
Ceren Polat ${ }^{1 \mathrm{a}}$ \\ ${ }^{1}$ Izmir Yasar University Department of Interior Architecture and Environmental Design, Izmir, \\ Turkey
}

\begin{abstract}
Any design works (except the art works) are designed for user(s). User's needs and abilities are the basic information to find the suitable solutions for the designers. Whether the product is an artwork or a design work, all of them have unique or well-known inspiration points. Finding an inspiration point, improving the idea, designing with the concept of the idea are processes that has been started to be taught to the designers in their first year Basic Design Classes at schools as the continuation of the principles and tools of design topics. With this study, the subject of Inspiration Point in Design implemented within the scope of the Basic Design I- studio course, taught to the first year students of the Department of Interior Architecture and Environmental Design at Yasar University as a class assignment.
\end{abstract}

Keywords:Basic design; Inspiration point; Abstraction; Iinterior architecture education; Design processes

\section{Introduction}

All designers should have an inspiration point prior to design their products for a specific use or need. At the very beginning of human nature, many inventions, design works and the other ideas usually were inspired from nature. Gravity, music, shelters, airplanes, building facades, artificial organs, jewelry and so many examples can be counted for this creation journey. Nature is an endless source for the creators and researchers and this inspiration will continue to grow.

Biomimicry or biomimetics is a new science that observes the materials in nature and then aim to produce solutions for humans by imitating these designs or by taking inspiration from them. The biomimicry concept discussed in this study is a new work area that selects the principles of nature and designs materials and processes in accordance with the principles that have ensured the continuity of life for 3.8 billion years. In short, biomimicry can be defined as "the innovation that gets inspired by nature" [1].

\footnotetext{
a Corresponding author: ceren.polat@yasar.edu.tr
} 
Calatrava's L'Hemisfèric also known as 'eye of knowledge' is a very significant example to show how designers/architects are taking inspiration from nature in their design works See Fig. 1. Built in the shape of the human eye, L'Hemisfèric is one of the structures within the City of Arts and Sciences in Valencia, Spain. Designed by architect Santiago Calatrava, L'Hemisfèric houses an IMAX theatre, a Planetarium and a Laserium. The "pupil" is the hemispherical dome of the IMAX theatre and the "eyelid" can open and close by using hydraulic lifts to operate the steel and glass shutter. This impressive architectural masterpiece is situated at the end of the dried up riverbed Turia. Calatrava wanted to bring water back to the area by creating a reflecting pool, which also serves as a stunning artistic display at night when the lighting creates an image of a whole eye [6].
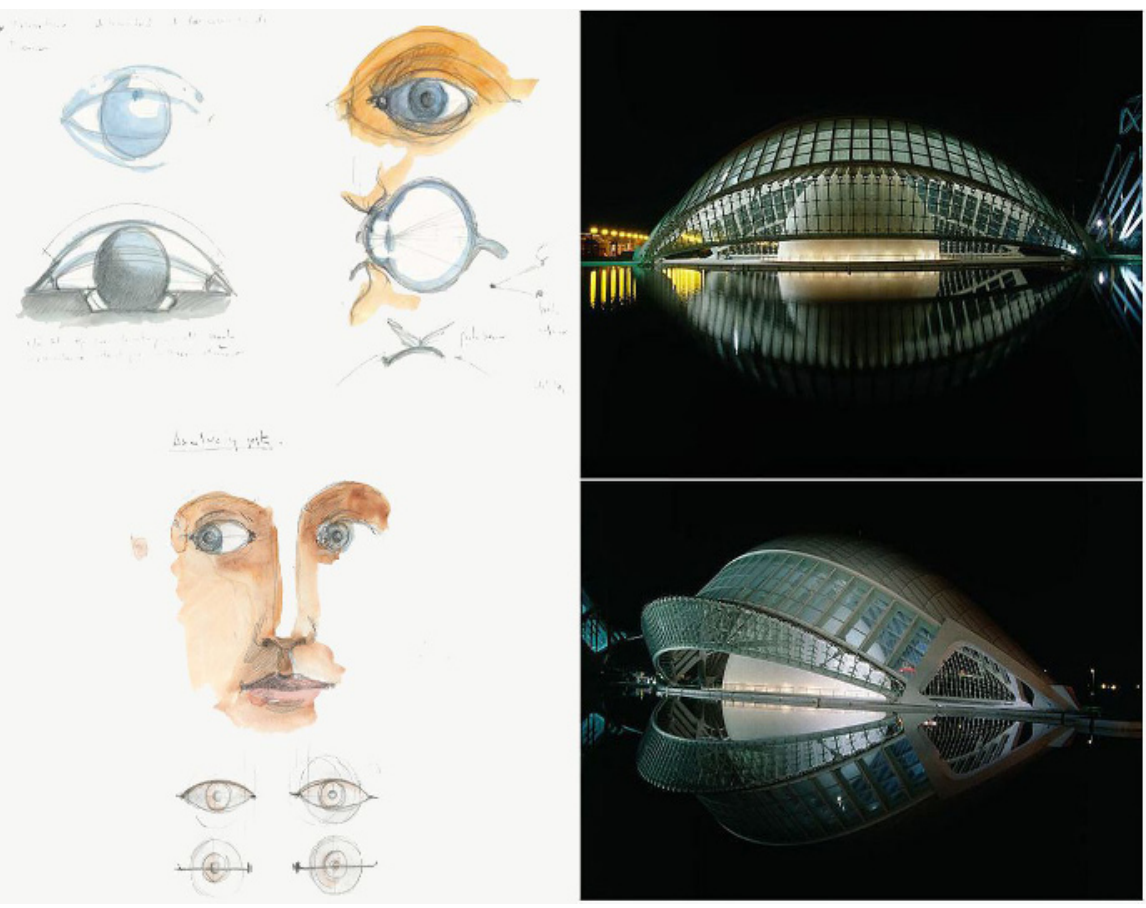

Fig. 1. (a) Calatrava's drawings [7, 8] (b) Calatrava's L'Hemisfèric, Valencia, Spain [9]

Architectural action starts with design. Without the action of design as space could not be attained, it would not be possible to talk about architecture where design does not exist. The design tools, designing methods and principles related to architecture were explained, classified and interpreted in different ways since the past and until the present by many researchers. Design tools are generally evaluated under two headings. According to Gurer (1990) design elements include points, lines, directions, dimensions, shape, value, texture and colour, while design principles can be listed as again repetition, harmony, order, hierarchy, domination, balance and union. As a methodical and theoretical proposition, Seylan categorized design tools (2005) as points, lines, surface, form, movement/motion, rhythm, balance and harmony. Dailey and Bryant, who discussed the design tools throughout the historical process, summarize design tools with the concepts of balance, unity, rhythm, proportion, colour interaction, figure/ground relationship (Daley \& Bryant, 2008). In design, the main idea is called "composition", while all of the aforementioned concepts are elements and principles, in other terms they are tools that can be used to create this composition. The way to create a space in the field of architecture is through the act of 
design. Apart from the aforementioned design tools, it is true that there is a relationship between creation of space and time, movement/motion, volume, form and many more concepts [2].

\section{Inspiration point in architectural design education}

In the interior architecture education, the environment is the source of information. In the perception of this information source, observation is an important element. The students should focus on the information and reach a conclusion by dissociating them from each other for the permanence of the information taught through the observation. In this sense, the abstraction technique enables the persistence by receiving the information learnt through observation into memory in parallel with the experiences [3].

Architectural design process has a complicated structure collecting data from various information areas. A designer solves design problem by interacting with different information areas at different stages of this process. Architectural representation techniques, which provide communication in problem solving, are one of these interactions. As an architect thinks on the solution, abstract design images occur in his/her mind, the architect then materializes and visualizes these images using representation tools [4].

3-D abstraction assignment was given to Basic Design I students at the end of their first semester as a final submission. They were responsible to use design tools and principles, while creating a new unit, as an abstracted form of influenced natural element. In the first step, they found an element from the nature, and started to draw sketches to make an abstraction of this element. Then they created a pattern that they used the pattern as a kind of floor plan. In the third step, they transform the 2-D pattern form into a 3-D form. With the multiple combination and connection of the units they design a 3-D Space Covering as their first structural design. See Fig. 2.
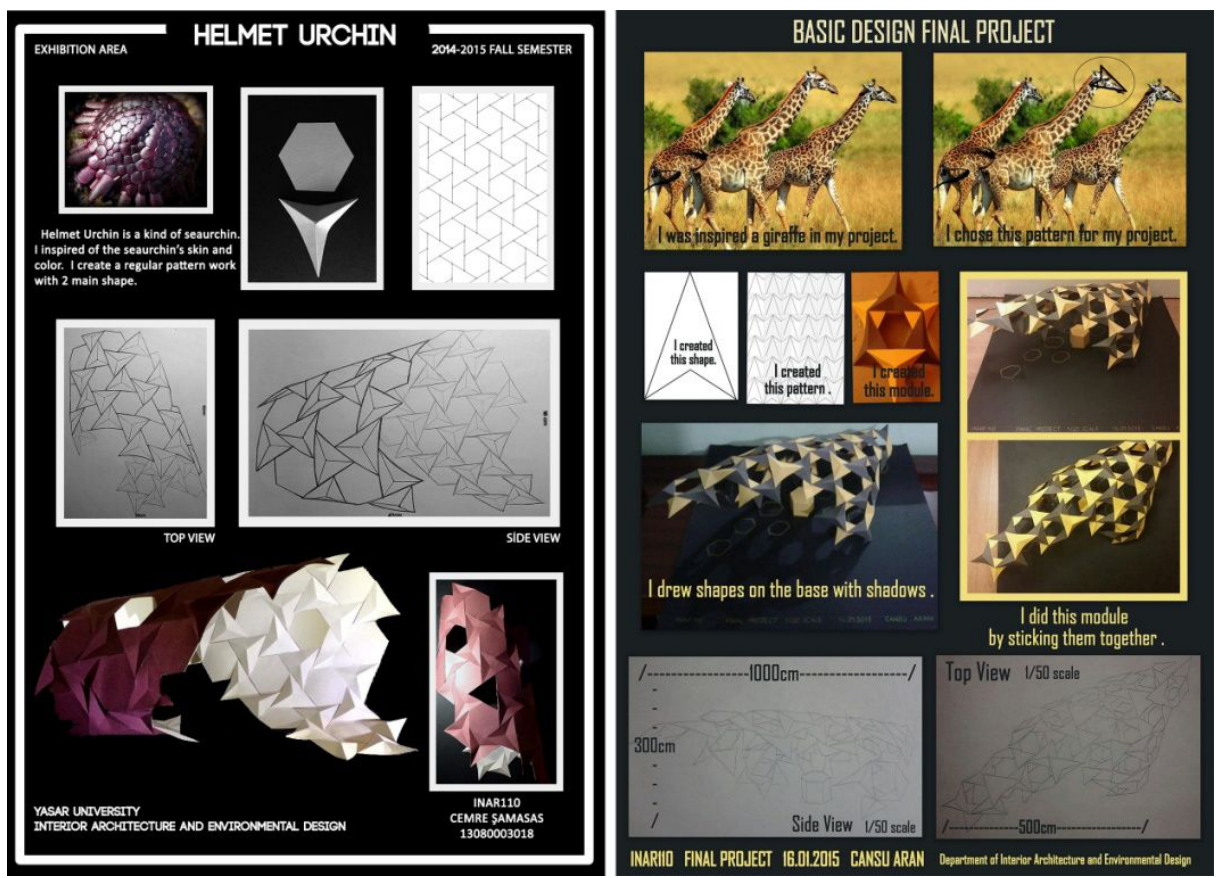

Fig. 2. Examples of student's submissions 


\section{Conclusions}

"Design Education" is an environment where information is directly transferred to the student and new solutions requested. The basic characteristic of the design education is the fact that the proposed new design of the student is criticized by the supervisor one by one. So, there is not unique correct solution for the given problem [5].

After this assignment students had an opportunity to see their improvement during the design processes in the studio by "Learning by doing" teaching method. They also improved their representation techniques about scaled drawings and model making, architectural photo shootings and poster design. They learned finding an inspiration point from nature as a starting idea and they transformed this idea to the concept of the project that finally they designed.

The main and important outcome of this assignment is to teach them how to design and to represent their project as a "whole" like the nature itself.

\section{References}

1. Tavsan, C., Tavsan, F., \& Sonmez, E. Biomimicry in Architectural Design Education. Procedia-Social and Behavioral Sciences, 182, 489-496, (2015).

2. Kuloglu, N. Teaching Strategies Learning Through Art: Music and Basic Design Education. Procedia-Social and Behavioral Sciences, 182, 395-401, (2015).

3. Tavşan, F. O., \& Küçük, P. Trial a New Learning Technique in Interior Design Education; The Abstraction of Furniture Components by Using Body Language and Sounds. Procedia-Social and Behavioral Sciences, 122, 98-104, (2014).

4. Yavuz, A. O., \& Yildirim, M. T. Study on Defining Utilization Steps of Tradiational and Digital Tools in Architectural Design Education. Procedia-Social and Behavioral Sciences, 51, 239-243, (2012).

5. Yildirim, T., Yavuz, A. O., \& Kirci, N. Experience of Traditional Teaching Methods in Architectural Design Education:"Mimesis Technique". Procedia-Social and Behavioral Sciences, 51, 234-238, (2012).

6. iDesignArch L'Hemisfèric: An Eye-Catching Architectural Masterpiece in Valencia, (2015). Retrieved from:http://www.idesignarch.com/lhemisferic-an-eye-catchingarchitectural-masterpiece-in-valencia/

7. moreAEdesign. More about: Valencia City of Arts - Valencia, Spain, (2012). Retrieved from:https://moreaedesign.wordpress.com/2012/09/13/more-about-valenciacity-of-arts-valencia-spain/

8. Aude-Barras. Santiago Calatrava - An interview with, (2013). Retrieved from: http://www.thegroundmag.com/santiago-calatrava-an-interview-with/

9. Calatrava, S. (2015). Retrieved from: http://www.calatrava.com/art/drawing-0010.html 